\title{
Why Colobus Monkeys (Colobus guereza) are Attracted to Human Settlements, and Urinate When They Come Across Humans in Their Territory and in Predator Dominant Places? Observation from Bale Mountains National Park, in Ethiopia
}

\author{
Israel Petros Menbere ${ }^{1 *} \quad$ Sefi Mekonen ${ }^{2}$ \\ 1.Department of Biology, College of Natural and Computational Sciences, Dilla University, Dilla, \\ Ethiopia \\ 2.Department of Wildlife and Ecotourism Management, Wolkite University, Wolkite, Ethiopia
}

\begin{abstract}
Colobus guereza is among the native African primates characterized by a having mainly black, short-haired tails with a small amount of white at the tip. The current study was made on groups of $C$. guereza found in Bale Mountains National Park, in the east of Rift Valley in Ethiopia. It is commonly called Colobus guereza gallarum though the taxonomy of this group has not been well-resolved. The aim of this paper was to identify the reasons for high abundance of the species in human settlements and related behavioural responses to human appearance in their territory following the recent observation made in Bale Mountains National Park. These issues were addressed through exploration of similar studies in different organisms including primates and referring various journals. The study indicated the high abundance of the species in human settlement has been associated with the need of protection from predators as interactions with humans can buffer non-human primates against the negative impact of environmental factors. Similarly, the urination of C. guereza was found to be anti-predator strategy, which has been demonstrated in combination with alarm calls, running back and forth, etc in other primates. The close attraction of $C$. guereza to human settlements can affect their existence either positively or negatively. Those unable to adapt to altered habitats will be forced into marginal habitat patches. While those that adapt, are able to live with the changing ecology and survive in agricultural systems often come into direct competition with humans. Similarly, the greater human-primate contact can increase pathogen transmission. Urination which was observed in C. guereza plays key roles in animal territorial defense and in prey-predator interaction. This overlooked behavioural aspect of primates is crucial in conservation of species.
\end{abstract}

Keywords: Attract, Colobus guereza, human settlements, territory, urination.

DOI: $10.7176 /$ ALST/75-02

Publication date:June $30^{\text {th }} 2019$

\section{Introduction}

Black and white colobus monkeys, or guereza (Colobus guereza), is among the few primate species which is a large glossy black monkey with a white mantle and a tail tuft. It is characterized by having mainly black, shorthaired tails with a small amount of white at the tip, forming apompom (Rabineau, 2009). The large and arboreal (Colobus guereza, Rüppell, 1835, is endemic to Africa (Butynski and de Jong, 2015).

Two groups of C. guereza are found in the Ethiopian highlands, one C. guereza in the west of the Rift Valley while the other group of $C$. guereza is found in the east of the Rift Valley including Bale Mountains National Park. C. guereza in the east is commonly called Djaffa Mountains Guereza and Colobus guereza gallarum. The taxonomy of this group of guereza is not well-resolved and phenotypic variations are used to identify the species. Similarly, the ecology of this taxon has been little known and even recognized as Data Deficient by IUCN (Gippolliti and Butynski, 2008). However, recently, studies focused on C. g. gallarum are increased significantly.

Although the geographic boundary of this subspecies is not well-defined (Caepaneto and Gippoliti, 2014), it has been observed to southward in agro-forestry ecosystems in Ethiopia. A recent survey of C. guereza in Bale Mountains National Park indicated the high abundance and record of the species in Rira, part in which human settlement is intense (Petros, et al., 2018a). Identifying reasons for closer attraction of guereza to human settlements and related behavioural responses to human appearance in their territory were found to be crucial. Hence, the aim of this review is to give an answer for following questions. 1) Why C. guereza are attracted to human settlements while living in Harenna Forest, which involves large tracts of tropical forest almost half of the BMNP (Caepaneto and Gippoliti, 2014). 2) Why the adult males of C. guereza urinate when they encounter humans in their territory and in predator dominant places? In order to address the above two questions, exploration of similar studies on other organisms including primates and referring various journals were undertaken. 


\section{Colobus guereza attraction to human settlements}

The growing human population combined with illegal hunting, habitat fragmentation and deterioration of natural areas are leading to the intense human and wild animals contacts (Wenz et al., 2009). Species that successfully inhabit modified areas cope with changing ecosystem patterns and processes, including altered predation risk and human presence, by adjusting their anti-predator strategies to local settings. Indeed, one of the most consistent patterns in risk taking is that animals in modified habitats have much shorter FID (flight initiation distance) (i.e. the individual delays fleeing from the risk) than those from areas with decreased human exposure. This effect has been widely attributed to animal's habituation to humans (typically associated with non-lethal interactions) and a relaxed predation risk around human settlements (Grolleet al., 2014; Díaz et al., 2013; Chapman et al., 2012). In populations living in anthropogenically fragmented forests or modified habitats, the characteristics of the fragments influence animal movements between, and long-term use of, the fragments (Kankama and Sicotte, 2013). Similarly, the survival of the species depends comprehensively on planning and implementing on the conservation and management of their food plants and habitat. For that reason, giving attention to conserve the plant and animals in the habitat are crucial (Petros et al., 2018b).

Habitats loss or deterioration usually results from habitat destruction which is induced by human activities and other inevitable factors. According to Petros et al., (2018a), the major threats of C. guereza observed during the study period included intensive livestock grazing, intensification of farming activities, logging, and other direct human disturbances (Figure 1). C. guereza were seen while living in close proximity to humans despite the different threats. This shows primates adapt human existence and live by changing their behaviour. The study on populations of vervet monkeys in human modified (urban) and natural (rural) environment indicated the delaying escape of individuals inhabiting human settlements compared to vervets inhabiting natural forest (Mikula et al., 2018).

Although the reasons to the attraction of guerzas to human settlements in BMNP require detailed studies, one factor leading gurezas to human modified environment might be the need of safeguard from predators. Interactions with humans can buffer non-human primates against the negative impact of environmental factors (Richard et al., 1989; Waite et al., 2007). C. guereza in the area live in proximity to humans or share sites with humans by modifying their behavior (Mikula et al., 2018). Similarily, adult male guerezas were observed urinating when they come in contact with humans in their natural forest territory and in predator dominant places. This urination behaviour continued for more than twice in some groups. Overall, the urination behaviour of adult males were encountered in 10 troops during the survey in different transects in the park (Petros et al., 2018a). This indicates that attraction of $C$. guereza to human settlement has some form of connection to predator avoidance.
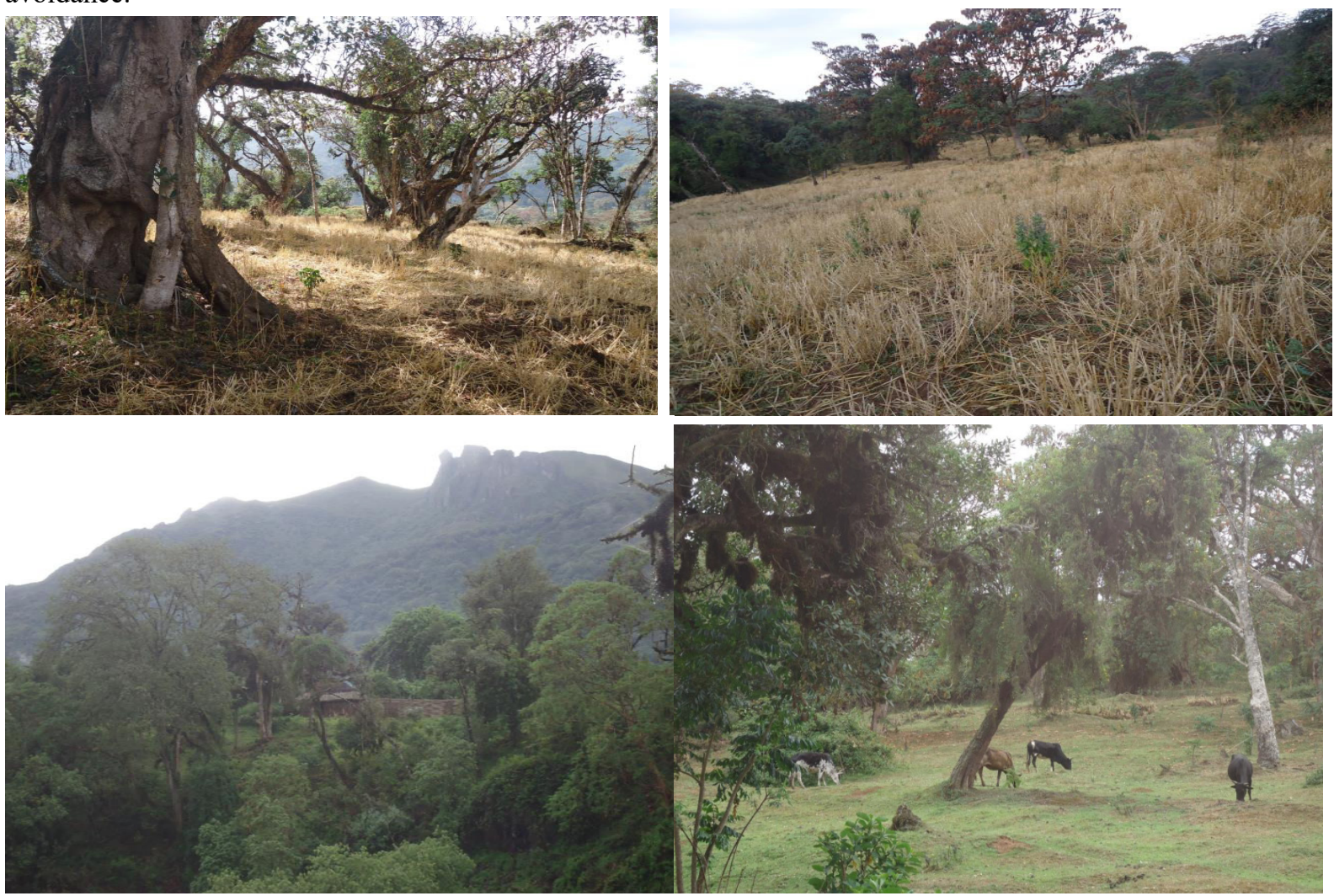

Fig1. Human modified habitats of (Colobus guereza, Photo by authors, 2016) 
Urination behaviour of Colobus guereza in the appearance of humans in their territory and in predator dominant places

Sources of scent in mammals include urine, faeces and glandular secretions. All excretions and sources of body odour can be detected by other animals, however, signals are intentional forms of communications whilst cues are incidental and can unintentionally provide information (Steiger et al. 2010). Urination is an important component of social communication in mammals. It is excretory by nature, and appeared as a means of marking for olfactory communication in animals that have not evolved specialized glands for pheromone secretion. Together with defecation and sweat excretion, urination is an obvious way by which animals might leave olfactory communicators. During the urine communication, the content of the urine permits communication of changes in the animal's physical and emotional states (Candland et al., 1980). The senses of smell in primates were not adequately understood until recently. However, currently it has been shown that both New and Old World primate species have well-developed olfactory sensitivity, which for some substances matches that of the rat or the dog (Prescott, 2006). The involvement of olfactory communication was observed in primate social behaviours, such as territorial defense (Mertl-Millhollen, 1988; Prescott, 2006), and a wide variety of information is coded in the scent marks (Prescott, 2006). Compared to other scents, urine has many advantages as a conveyor of information. It is readily available and, to some degree, under voluntary control. Because it changes constantly in composition, it may communicate information regarding the internal state of the producer. One of the more interesting components of urine is adrenalin which is thought to be secreted in response to a variety of hormonal activities that accompany stress (Candland et al., 1980).

Observations from field studies indicate that primate populations of various species adjust their behavior according to the perceived risk of being preyed upon (Bettridge et al., 2010; Oliveira and Dietz, 2011). The study of (Kano, 1983), indicated pygmy chimpanzees were urinated and defecated when humans approached their territory. This anti-predation strategy of pygmy chimpanzees was supported with giving alarm calls, ran back and forth on a branch, scowling and striking his foot, or less commonly his hand, on the branch. The urination by C. guereza in the appearance of humans in their territory in BMNP might have similar relationship of the above strategy. Similarly, the response of $C$. guereza to human approach in predator dominant places was characterized by urination and fleeing from the risk. This indicates that urination can be considered as one form of antipredation strategy in $C$. guereza. This urination behavior has been displayed by adult male that stays a bit far from the group. During this time, adults were heard making alarm calls and observed when scanning the surrounding with some kind of movement. This is similar to many studies in which adult males usually display various anti-predator behaviours (Ouattara et al., 2009). Males typically engage in more vigilance or more risky behaviours (approaching, counter-attacking) than females (Zuberbühler et al., 1997).

\section{Ecological implications of Colobus guereza attraction to human settlements}

Humans have always been shared habitats with nonhuman primates. However, the dynamics of human-primate interactions have changed dramatically in the recent past (Gillespie et al., 2008). The high human population growth leads to increasing encroachment of wildlife habitats and increases in human-wildlife conflicts (Siex and Struhsaker, 1999). The increasing attraction of C. guereza to human settlements in BMNP might lead to the following effects. Groups of $C$. guereza that are unable to adapt to altered habitats will be forced into small, mariginal habitat patches. While those that adapt, because of their behavioural flexibility, are able to live with the changing ecology and survive in agricultural systems often come into direct competition with humans and are persecuted as pests (Siex and Struhsaker, 1999). As human population density continues to increase exponentially, speeding the reduction and fragmentation of primate habitat, greater human-primate contact is inevitable and higher rates of pathogen transmission are likely (Gillespie et al., 2008). In addition, the presence of humans and an environment modified by humans can lead to substantial changes in the community structure of intestinal helminthes in wild non-human primates (Wenz et al., 2009).

\section{Urination and its importance in conservation of Colobus guereza}

Adequate knowledge of animal behaviour, such as social behaviour, prey-predator interaction and movement are vital to develop theories and methodology to the successful conservation and management of wildlife (Palmer and Rosell, 2011). Chemical communication is one behavioural aspect of animals, but its potential relevance in conservation has often been overlooked (Palmer and Rosell, 2011). Scent manipulation and olfaction have great roles in animal territorial defense and in prey-predator interaction that aid conservation of species. Linklater (2004) and Swaisgood (2007), emphasized the need of studying scent manipulation and the role of olfaction in conservation. Ignoring olfaction has detrimental consequences on how we view and manage a species (Palmer and Rosell, 2011).

\section{Conclusion}

This rough assessment and review indicates as nonhuman primates may live in close contact with humans even 
leaving the highly forested habitats. One main reason revealed for this proximity is avoiding predator pressure. The study made in Harrenna forest indicated the high abundance of guereza in human involved environments than purely natural habitat. Similarly, the urination of guereza was detected when they encounter humans in their territory mainly in habitats far away from humans. But, urination behaviour was observed coupled with fleeing in the predator dominant habitats. This shows urination has some form link with anti-predator behaviour of guerezas in BMNP.

\section{References}

Bettridge, C., Lehmann, J., Dunbar, R.I.M., (2010). Trade-offs between time, predation risk and life history: and their implications for biogeography: a systems modelling approach with a primate case study. Ecol. Model. $221,777-790$.

Butynski, T.M. and de Jong, Y.A. (2015). Distribution and Conservation Status of the Mount Kilimanjaro Guereza Colobus guereza caudatus Thomas, 1885. Primate Conservation, (29):107-113.

Caepaneto, G.M. and Gippoliti, S. (2014). Primates of the Harenna Forest, Ethiopia. News from the field Africa, Primate conservation 11-15.

Candland, D. K., Blumer, E.S. and Mumford, M. D. (1980). Urine as a communicator in a New World primate, Saimirisciureus. Animal Learning \& Behavior1980,8 (3),468-480.

Chapman, T., Rymer, T., Pillay, N., 2012.Behavioural correlates of urbanisation in the Cape ground squirrel Xerusinauris. Naturwissenschaften 99, $893-902$.

Díaz, M., Møller, A.P., Flensted-Jensen, E., Grim, T., Ibáñez-Álamo, J.D., Jokimäki, J., Markó, G., Tryjanowski, P., 2013. The geography of fear: a latitudinal gradient in anti-predator escape distances of birds across Europe. PLoS One 8, e64634.

Gillespie, T.R., Nunn, C.L. and Leendertz, F.H (2008). Integrative Approaches to the Study of Primate Infectious Disease: Implications for Biodiversity Conservation and Global Health. Year Book of Physical Anthropology 51:53-69.

Gippolliti, S. and Butynski, T. M. (2008). Colobus guerezassp. gallarum. In: IUCN 2013. IUCN Red List of Threatened Species. Version 2013.2.<www.iucnredlist.org>. Downloaded on 12 January 2016.

Grolle, E.K., Lopez, M.C., Gerson, M.M., 2014. Flight initiation distance differs between populations of western fence lizards (Sceloporus occidentalis) at a rural and an urban site. Bull. South. Calif. Acad. Sci. 113, $42-$ 46.

Kankama, B.O. and Sicotte, P. (2013). The Effect of Forest Fragment Characteristics on Abundance of Colobus vellerosus in the Forest-Savanna Transition Zone of Ghana. Folia Primatol 2013; 84:74-86.

Kano, T. (1983). An ecological study of the pygmy chimpanzees (Pan paniscus) of Yalosidi, Republic of Zaire. International Journal of Primatology 4:1-31.

Linklater, W.L. (2004). Wanted for conservation research: behavioural ecologists with a broader perspective. BioScience 54, 352-360.

Mertl-Millhollen, A.S. (1988). Olfactory demarcation of territorial but not home range

boundaries by Lemur catta. Folia Primatologica 50(3-4), 175-187.

Mikula, P., Šaffa, G., Nelson, E. Tryjanowski, P. (2018). Risk perception of vervet monkeys Chlorocebus pygerythrus to humans in urban and rural environments. Behavioural Processes 147 (2018) 21-27.

Oliveira, L.C., Dietz, J.M., (2011). Predation risk and the interspecific association of two Brazilian Atlantic forest primates in Cabruca agroforest. Am. J. Primatol. 73, $852-860$.

Ouattara,K., Lemasson, A. and Zuberbühler, K. (2009). Anti-predator strategies of free-ranging Campbell'smonkeys. Published in Behaviour, Vol. 146, No. 12, p. 1687-1708.

Palmer, R.C. and Rosell, F. (2011). The Importance of Chemical Communication Studies to Mammalian Conservation Biology: a review, Telemark University College, N-3800 Bø i Telemark.

Petros, I., Mekonen, S., Gena, H. and Mesfin, Y (2018a). Population Status, Distribution, and Threats of Colobus guereza gallarum in Bale Mountains National Park, Southeastern Ethiopia. International Journal of Natural Resource Ecology and Management. Vol. 3, No. 3, 2018, pp. 39-45. doi: 10.11648/j.ijnrem.20180303.12

Petros, I., Mekonen, S., Gena, H., Mesfin, Y . (2018b). Feeding and Ranging ecology of Colobus guereza gallarum in Bale Mountains National Park, Southeast Ethiopia. J Biodivers Endanger Species 6: 007. doi:10.4172/2332-2543.S2-007

Prescott, M. (2006). Primate sensory capabilities and communication signals: implications for care and use in the laboratory. National Center for the Replacement, Refinement and Reduction of Animals in Research, pp. 1-23. London. http: //www.nc3rs.org.uk

Rabineau, J, (2009). Integrated non-invasive investigations of captive Abyssinian colobus monkeys (Colobus guereza): behaviour, stress and parasitism. University of Exeter, PhD dissertation, London.

Richard, A.F., Goldstein, S.J., Dewar, R.E., (1989). Weed macaques: the evolutionary implications of macaque 
feeding ecology. Int. J. Primatol. 10, 569 -594.

Siex, K.S. and Struhsaker, T.T. (1999). Colobus monkeys and coconuts: a study of perceived Human-wildlife confilcts. Journal of Applied Ecology, 36, 1009-1020.

Steiger, S., Schmitt, T. and Schaefer, H.M., (2010). The origin and dynamic evolution of chemical information transfer. Proceedings of the Royal Society B doi:10.1098/rspb.2010.2285.

Swaisgood, R.R., (2007). Current status and future directions of applied behavioural research for animal welfare and conservation. Applied Animal Behaviour Science 102, 139-162.

Waite, T.A., Chhangani, A.K., Campbell, L.G., Rajpurohit, L.S., Mohnot, S.M., (2007). Sanctuary in the city: urban monkeys buffered against catastrophic die-off during ENSO-related drought. EcoHealth 4, 278 -286.

Wenz, A., Heymann, E.W., Petney, T.N. and Taraschewski, H. F. (2009). The influence of human settlements on the parasite community in two species of Peruvian tamarin. Parasitology; 137, 675-684.

Zuberbühler, K., Noë, R. and Seyfarth, R.M. (1997). Diana monkey long-distance calls: messages for conspecifics and predators. Anim. Behav. 53: 589-604. 